\title{
REGIONAL PRIORITIES IN DESIGNING SUSTAINABLE ARCHITECTURE BASED ON CLEAN AND RENEWABLE ENERGY IN TEHRAN
}

\author{
Soha Khasseh \\ Islamic Azad University, Architectural Engineering, Central Tehran Branch, Tehran, Iran; \\ *Corresponding Author Soha Khasseh , e-mail: khasseh@aftermail.ir;
}

Received April 2021; Accepted May 2021; Published June 2021;

DOI: $\underline{\text { https://doi.org/10.31407/ijees11.338 }}$

\begin{abstract}
Achieving appropriate design solutions to achieve the goals of sustainable architecture and creating a residential complex based on clean energy and concerning climatic characteristics and the use of technology, is one of the most important needs of the country based on architectural vision documents for the next ten years. Localization or regulation of measurement strategies and then research of global standards of sustainable architecture is very important in this field and therefore this research considered the way to achieve the lead standard. In measuring the lead characteristics before each study, the regional scores index should be extracted and introduced in the regional study of regional sustainability priorities, and such a study did not exist in Tehran. The purpose of this study is to achieve a strategic priority classification responsive to Tehran's climate that can be the basis for measuring the success of sustainable projects and such designs, so based on areas that have this advantage, such as examples in Southern California, the project in India, Arizona, and many other regions that have this privilege, it was found that regional priority credits are determined according to its sub-criteria, based on which 130 questionnaires were surveyed among architects and civil engineers. In master's and doctoral degrees and using descriptive statistics, inference by SPSS software and credits that had the highest percentage as regional priorities, respectively, reducing water consumption, renewable energy in place, optimizing energy consumption, optimizing water consumption, waste management, and green energies were identified.
\end{abstract}

Keywords: regional priorities, sustainable architecture, clean and renewable energy, green energies 